\title{
Surgical Approaches in the Repair of Laterofacial Loss
}

\author{
Mabika Bredel Djeri Djor*, Kabbaj Houda, Garango Allaye, Saad Lahimiti, Saad Fawzi, \\ Mansouri Nadia Hattab
}

Oral and Maxillo-facial Surgery Department, Faculty of Medicine and Pharmacy, Cadi Ayyad University, Marrakech, Morocco

\author{
Email address: \\ bredmabika@gmail.com (M. B. D. Djor) \\ ${ }^{*}$ Corresponding author
}

\section{To cite this article:}

Mabika Bredel Djeri Djor, Kabbaj Houda Houda, Garango Allaye, Saad Lahimiti, Saad Fawzi, Mansouri Nadia Hattab. Surgical Approaches in the Repair of Laterofacial Loss. International Journal of Clinical Oral and Maxillofacial Surgery. Vol. 5, No. 2, 2019 , pp. 37-41. doi: 10.11648/j.ijcoms.20190502.11

Received: May 31, 2019; Accepted: July 9, 2019; Published: August 28, 2019

\begin{abstract}
The purpose of this work is to describe the surgical approach in some situations of laterofacial loss, which pose a problem concerning the moment of their repair and the choice of the technique to be used considering the attainment of noble elements. The study provides a descriptive and cross sectional study with retrospective data collection, conducted in the department of Maxillofacial and Aesthetic Surgery of the Mohammed 6 Teaching Hospital of Marrakech, on 82 cases of laterofacial cutaneous loss secondary to trauma and post tumor excision collected during 3 years. Etiologies were dominated by tumors in $60,97 \%$ of cases and trauma in $39,04 \%$. The most frequent location was frontal and temporal in $41,46 \%$ of cases. Nobles elements were injured in $15,85 \% .87,5 \%$ of traumatized patients had a primary reparation with locoregional flaps, while secondary reparation was proposed to $93,33 \%$ with malignant tumors until reception of histological results. The repair of laterofacial defects is subject to certain requirements before any surgery. Whenever usable, the locoregional reserve seems to us the most appropriate means of reconstruction.
\end{abstract}

Keywords: Repair, Tumors, Trauma, Laterofacial Loss, Flaps

\section{Introduction}

The face, the anterior part of the cephalic extremity, is a real functional and aesthetic crossroads. It represents a means of expression, and is considered as social passport of the individual. It is made up of several subunits. The lateral part contains many functional elements. It remains unprotected and therefore exposed to traumatic or tumoral aggressions, which can cause defects of variable sizes with possible threat of neuroglandular noble structures (parotid duct and branches of the facial nerve) requiring codified management.

This management must consider the anatomo-clinical complexity of the lesions, the threat of noble elements, the extent of the defect, and the state of the surrounding tissues.

The purpose of our study was to describe our surgical approach on repairing laterofacial loss insisting on repair timing and techniques to improve functional and aesthetic results.

\section{Patients and Methods}

\subsection{Type and Period of Study}

A descriptive and cross sectional study with retrospective data collection, conducted in the department of Maxillofacial and Aesthetic Surgery of the Mohammed 6 Teaching Hospital of Marrakech, over a period of 3 years from January June 2013 to June 2016 with a mean follow-up of 18 months. Our sample consisted of 82 patients that we classified into two groups according to the etiology which was essentially tumoral (G1) and traumatic (G2).

\subsection{Variables Studied}

The following variables have been studied: Age, sex, the general and nutritional state, etiology of the loss substance, topography of the loss of substance, preoperative clinical characteristics of defect, postoperative morphological profile (occlusion type, degree of advancement of the chin, oral 
opening), type of anesthesia, duration of repair, type of surgery, the timing of repair, and the surgical approach.

\subsection{Surgical Approach}

The main objective was to ensure either a functional and aesthetic results, that are the closer possible to restitution ad integrum, as the socio-professional pressure is important nowadays.

It was personalized and codified in stages:

1. The verification if noble elements are injured. The parotid duct is exceptionally exposed because of its deep location, except in cases of highly invasive tumor where lesions ought to be explored and sometimes ligated. The facial nerve can be also injured specially its mandibular branch because it is too superficial.

2. The importance of asepsis in posttraumatic loss of substance by a good minimal trimming and an abundant washing with physiological serum.

3. The insurance that margins of excision are carcinological especially in malignant tumors where it should be up to $1 \mathrm{~cm}$. The limits of excision were as follows: from $4 \mathrm{~mm}$ for basal cell carcinoma, up to 10 $\mathrm{mm}$ in some aggressive forms (sclerodermiform type), $10 \mathrm{~mm}$ for squamous cell carcinoma, and from $10 \mathrm{~mm}$ to $35 \mathrm{~mm}$ for melanomas depending on their type and their thickness essentially.

4. The evaluation of the locoregional tissue reserve in view of the realization of the locoregional or distant flaps which are chosen depending on the defect, the local conditions and the habits of the surgeon.

5. The choice of the timing of reparation:

a) primary management: in traumatic and clean defects, and benign tumor.

b) deferred primary repair 48 to $72 \mathrm{~h}$ : was undertaken for traumatic moderately soiled defects.

c) secondary management: in very soiled traumatic defects, and in malignant tumors were anatomopathology confirmation was needed first (reparation was in the second week after the first intervention).

6. Prioritize repair steps:

a. repair of the noble elements first if they are reached.

b. butt suture of the parotid duct after catheterization. c. closing of the defect by total skin grafting, directed cicatrization, locoregional or distant flaps.

\section{Result}

The mean age was 27.5 years old for traumatic defects versus 58 years old for tumors. $71.87 \%$ of the traumatic defects were male compared to $70 \%$ for tumor defects.

The origin of defects was tumoral in $60,97 \%$ cases (G1), of which $90 \%$ were malignant. $93.33 \%$ of tumors had previous biopsies. The traumatic origin was in $39.02 \%$. It was mainly related to road accidents (43.75\%) followed by aggressions (34.37\%), bites $(9.77 \%)$, bullet wound in $6.25 \%$ and others.

The topographic distribution of defects was dominated by temporofrontal localization in $41.4 \%$ of cases, cervicojugal $25.60 \%$, eyelid $14.63 \%$, auricular $9.75 \%$, lip commissure $4.87 \%$ and multiple locations were found in $3.65 \%$ of cases.

Damage of a noble element, particularly the branches of the facial nerve and parotid duct, was found in $12.5 \%$ of traumas and $18 \%$ after tumor excision.

The repair was done under locoregional anesthesia in $81.25 \%$ of traumatic defects and $44 \%$ tumor defects.

An immediate repair was performed in $87.5 \%$ of traumatic cases and $36 \%$ for of tumor cases. $71.11 \%$ of the wounds for malignant tumors were repaired secondary, we report also case of primary repair after extemporaneous examination.

Several repair techniques were performed and were independent of etiology (Table 1).

Table 1. Reconstruction techniques.

\begin{tabular}{ll}
\hline Reconstruction techniques & Number of patients \\
\hline Heal by second intention & 7 \\
Total skin graft & 7 \\
H-slip flap & 29 \\
Mustardé rotation advencement flap & 15 \\
Cervical flap & 5 \\
Eslander heterolabial flap & 4 \\
Hetero eyelid flap & 4 \\
Partial otopoeise partielle & 8 \\
Other & 4 \\
\hline
\end{tabular}

Some illustrations of the techniques mentioned above (Figure 1. et Figure 2.)

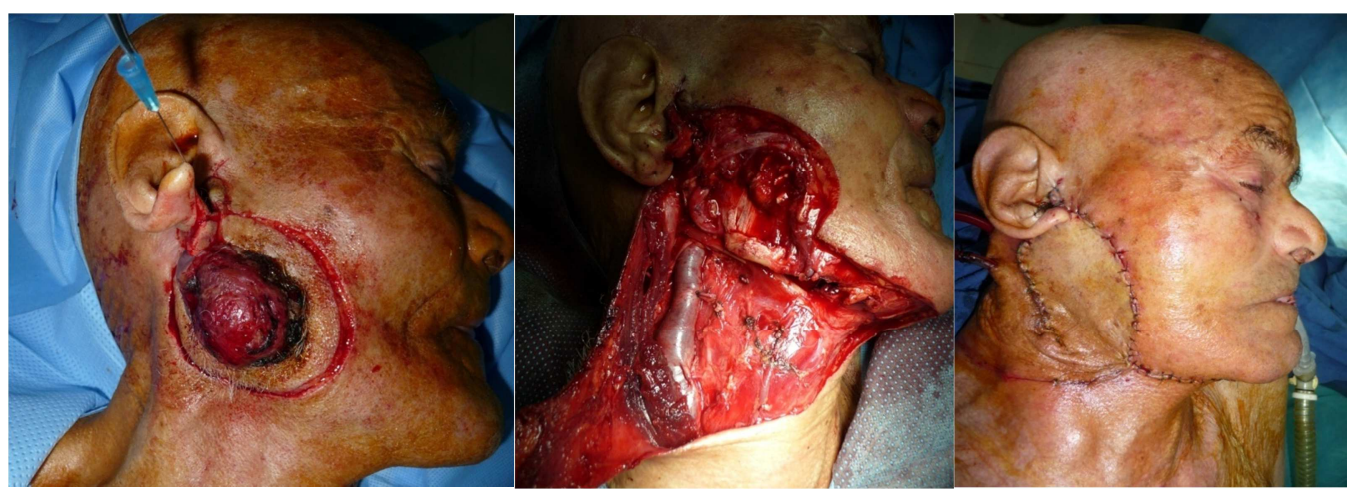

Figure 1. Cervicojugal defect repaired by bifolate cervical flap. 


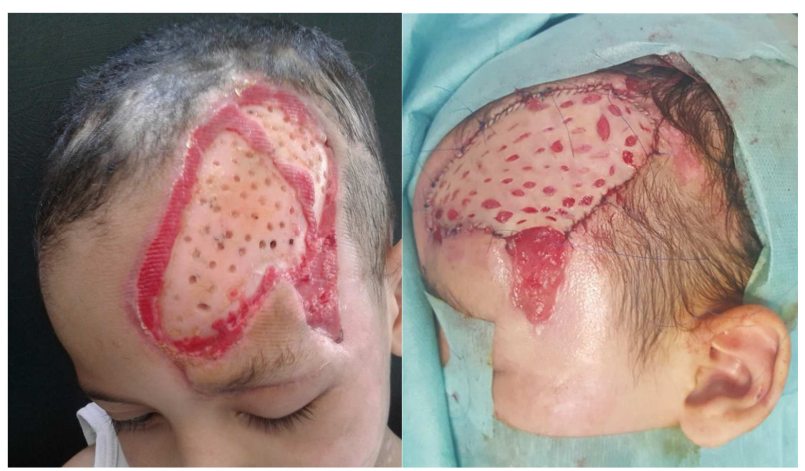

Figure 2. Temporofrontal defect repaired by total skin graft after spongiolization.

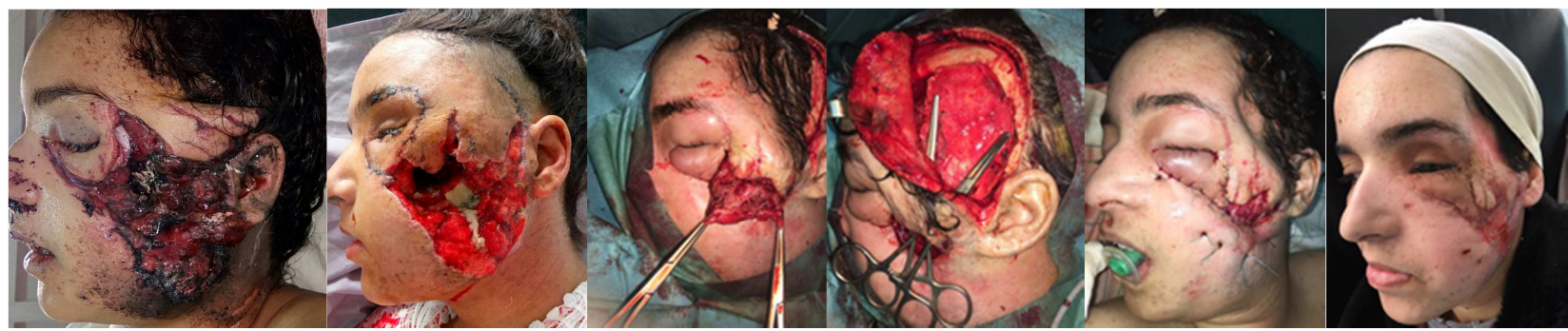

Figure 3. Cheek defect by firearm repaired via healing by secondarily intention followed by temporal transposition flap.

The most common complications in the early postoperative period are infection, flap suffering, necrosis (Table 2).

Table 2. General characteristics of the postoperative recoveries according to the groups.

\begin{tabular}{lll}
\hline Characteristics & G1 (tumor) & G2 (traumatic) \\
\hline Infectious complications & Less pronounced & More pronounced \\
Suffering flap & Less pronounced & More pronounced \\
& a case of total necrosis & No case of necrosis \\
Functional sequelae & Acceptable & Less pronounced \\
& Good $90 \%$ & Good $90,63 \%$ \\
Result & Average $6 \%$ & Average $9,37 \%$ \\
& Bad $4 \%$ & Bad $0 \%$ \\
\hline
\end{tabular}

No cases of perioperative death were noted in our serie.

\section{Discussion}

Laterofacial loss remain a challenge for the plastic surgeon. They make each patient a special case, requiring a personalized and codified treatment regimen.

The timing of the repair and the choice of technique remains paramount.

Our epidemiological parameters are similar to those of the literature with an average age of 27.5 years for traumatic defects compared to 58 years for tumors. $71.87 \%$ of traumatic defects were in male compared to $70 \%$ for tumors [1].

Therapeutic indications of primary repair, delayed repair and secondary repair are still controversial.

On one hand, primary repair has the advantage of minimizing the healing via secondary intention which is unsightly in the face because of its retracting and demanding nature for the patient and the surgeon. On the other hand, it also reduces the phenomena of infection and inflammation that follow. In this way, the patient can avoid the psychological experience of disfigurement by reducing the number of interventions and the duration of care with simpler postoperative follow-up. It is, therefore, a more economical technique.

This repair also concerns defects caused by human or animal bites (figure 4). Indeed, Javaid et al evaluated the morphological and functional results in 40 patients who received primary repair for defects of the face following dog bites. Of the nine local flaps and skin grafts used, they noted partial necrosis on a single flap [2]. The infection rate associated with mammalian bites is $6 \%$ [3]; similarly, human bites can be repaired immediately with good results [4]. Primary repair seems to reduce the occurrence of infection [5]. 


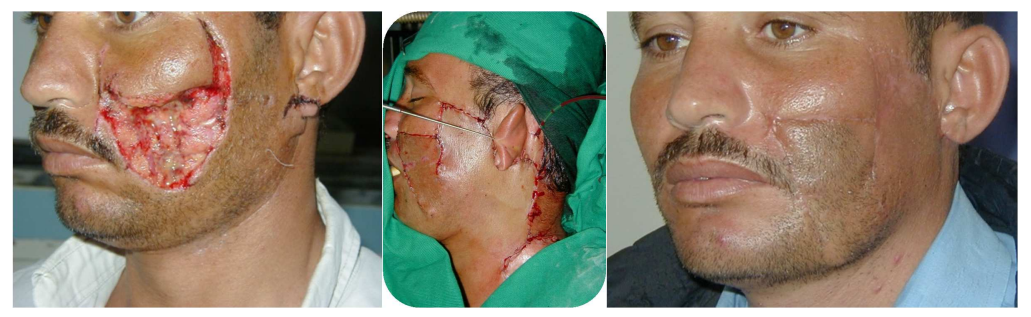

Figure 4. Cheek defect caused by animal bite repaired by a lower pedicle trifoliate flap.

Even interesting, primary repair must be subject to certain requirements for which no surgical activism should be undertaken.

The availability of the technical platform and an experienced surgical team is imperative. Indeed, this repair often uses locoregional flaps (Figure 3) where only the surgeon's experience can guarantee a maximum of success and preserve other means of reconstruction for a secondary repair that is surer [6-8].

Our series has few cases of facial defects due to gunshot wounds, which were repaired either immediately or secondarily depending on the degree of taint. Immediate repair in these cases is widely recommended in the literature [9]; it reduces the phenomena of infection and retraction and limits the number of interventions.

The auricle is a cutaneo-cartilaginous structure sensitive to infections. The primary or secondary reconstruction of its defects uses various techniques, microsurgical and nonmicrosurgical. We realized in 8 patients a partial reconstruction of the auricle using a cartilaginous model taken from costal cartilage (Figure 5.), one replantation according to the technique of Mladick in a patient with a clear section of the auricle and 2 Crikelair flaps (Figure 6). No case of epithesis [10].

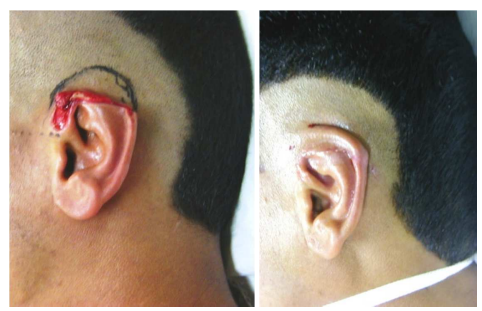

Figure 5. Traumatic loss of the upper third of the auricle repaired by partial otopoiesis.

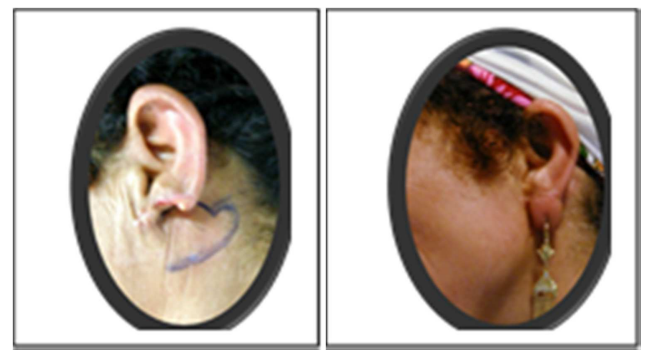

Figure 6. Crikelair flap for repair of the lobule of the ear.

We used several techniques to repair defects considering the basic principles governing any facial reconstruction including the principle of tissue identity, aesthetic units of the face and the notion of function inseparable with aesthetic considerations. We favor flaps advancing by banks dissection, local and locoregional flaps (Figure 7), skin grafts for extensive and superficial defects and replantation of the amputated part by microsurgery or special technique: Mladick [11-13].

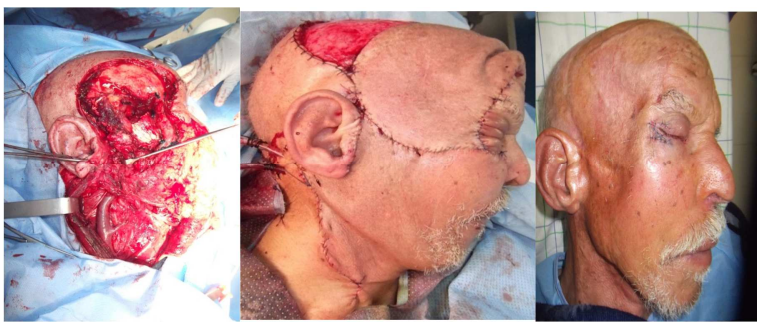

Figure 7. Hemiface defect repaired by cervical and converse flap

For defects whose dimensions exceeded the possibilities of repair by locoregional flaps, free vascularized transfers seems a good alternative (Figure 8) [14, 15].

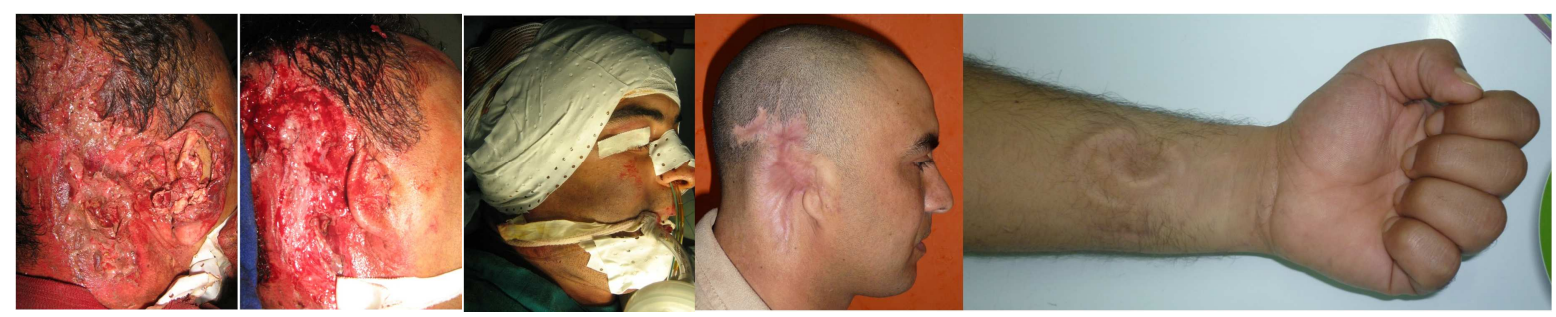

Figure 8. Cervicotemporoauricular defect left to heal by second intention and then repaired by Chinese flap.

\section{Conclusion}

Laterofacial loss are more and more frequent and serious.
They involve the functional and aesthetic prognosis of patients, and must therefore require a safe method of management with ways of starting allowing both good 
surgical technic and better timing. For the sake of a better functional than morphological result and to avoid the risk of sequelae, the surgical approach of the repair must take into account the attainment or not of the noble elements, the healthy profile of the defect and realize the repair as soon as possible. This as complete as possible treatment allows the patient to regain quickly an acceptable socioprofessional life. But, when untreated or insufficiently treated, laterofacial loss can present severe long term complications and/or aesthetic deformities.

\section{Conflicts of Interest}

The authors declare no conflict of interest.

\section{References}

[1] Cotofana S, Fratila AA, Schenck TL, et al. The anatomy of the aging face: a review. Facial Plast Surg 2016; 32 (3): 253-60.

[2] Javaid M, Feldberg L, Gipson M: Primary repair of dog bites to the face: 40 Cases. J R Soc Med 91: 414, 1998.

[3] Chen E, Hornig S, Shepherd SM, et al: Primary closure of mammalian bites. Acad Emerg Med 7: 157, 2000.

[4] Donkor P, Bankas DO: A study of primary closure of human bite injuries to the face. J Oral Maxillofac Surg 55: 479, 1997.

[5] Herford AS, Early Repair of Avulsive Facial Wounds Secondary to Trauma Using Interpolation Flaps, J Oral Maxillofac Surg 62: 959-965, 2004.

[6] Gulleth Y, Goldberg N, Silverman RP, Gastman BR. What is the best surgical margin for a Basal cell carcinoma: a metaanalysisof the literature. Plast Reconstr Surg 2010; 126 (4): 1222-31. http://dx.doi.org/10.1097/PRS.0b013e3181 ea450d.
[7] Lan Loo E, Mosterd K, Krekels GA, Roozeboom MH, Ostertag JU, Dirksen CD, et al. Surgical excision versus Moh's micrographic surgery for basal cell carcinoma of the face: a randomised clinical trial with 10 year follow-up. Eur J Cancer $\quad 2014 ; \quad 50 \quad$ (17): $3011-20$. http://dx.doi.org/10.1016/j.ejca.2014.08.018 [Epub 2014 Sep 25].

[8] Mehta RP. Surgical treatment of facial paralysis. Clin Exp Otorhinolaryngol. 2009; 2 (1): 1-5.

[9] Motamedi $\mathrm{MH}$, Behnia $\mathrm{H}$ : Experience with regional flaps in the comprehensive treatment of maxillofacial soft-tissue injuries in war victims. J Craniomaxillofac Surg 27: 256, 1999.

[10] Firmin F, Marchac A. Reconstruction of the burned ear. Ann Chir Plast Esthet 2011; 56: 408-16.

[11] Bourdais, L., Perrot, P., Kitsiou, C., Martin, G., Bellier-Waast, F., \& Duteille, F. (2014). Le lambeau de fascia superficialis temporalis pédiculé pour la couverture des pertes de substance de la face. Revue de Stomatologie, de Chirurgie MaxilloFaciale et de Chirurgie Orale, 115 (1), 56-61. doi: 10.1016/j.revsto.2013.05.005.

[12] Barthelemy I. Chirurgie secondaire des tumeurs cutanées de la face. Ann Chir Plast Esthet (2019), https://doi.org/10.1016/j.anplas.2019.04.003.

[13] Lukavsky R, Linkov G, Fundakowski C. A novel approach to submandibular gland ptosis: creation of a platysma muscle and hyoid bone cradle. Arch Plast Surg 2016; 43 (4): 374-8.

[14] Nadig S, Schooler W, Wax MK, Free tissue reconstruction of traumatic soft-tissue defects. Operative Techniques in Otolaryngology (2008) 19, 145-150.

[15] Wong CH, Wei FC. Microsurgical free flap in head and neck reconstruction. Head Neck 2010; 32: 1236-45. 